\title{
Microwave-Assisted Synthesis and Assembly of Hyperbranched su- pra Quantum Dot CdE (E = S, Se, Te) Nanocrystals
}

\author{
Mohammad S. Yazdanparast and Emily J. McLaurin* \\ Department of Chemistry, Kansas State University, Manhattan, KS 66506
}

Index

Page

Figure S1. Image of samples of NCs obtained from reactions with different ratio of $\mathrm{Me}_{2} \mathrm{~S}_{2}$ and $\mathrm{Ph}_{2} \mathrm{Se}_{2}$

Figure S2. HRTEM image of HSQDs obtained from dichalcogenides with $12 \% \mathrm{Ph}_{2} \mathrm{Se}_{2}$.

S1

S1

Figure S3. TEM image and histogram of arm length of NCs obtained from samples with $6 \%, 12 \%$ and $34 \% \mathrm{Ph}_{2} \mathrm{Se}_{2}$.

Figure S4. UV-Vis spectrum of NCs obtained from dichalcogenides with $12 \% \mathrm{Ph}_{2} \mathrm{Se}_{2}$ over time.

S2

Figure S5. Individual and aggregated branched NCs obtained from $10 \% \mathrm{Ph}_{2} \mathrm{Se}_{2}$

$\mathrm{S} 2$

Figure S6. UV-Vis spectrum of NCs obtained from reaction of diluted mixture at $250{ }^{\circ} \mathrm{C}$.

Figure S7. HRTEM image of NCs obtained from reaction of diluted mixture containing $10 \% \quad$ S3 $\mathrm{Ph}_{2} \mathrm{Se}_{2}$ at $250{ }^{\circ} \mathrm{C}$.

Figure S8. TEM images and histogram of arms length and thickness of NCs obtained from samples $10 \% \mathrm{Ph}_{2} \mathrm{Se}_{2}$ at different temperatures.

Figure S9. UV-Vis spectra of CdSe NCs obtained from reaction of Cd(oleate) $)_{2}$ with $\mathrm{Ph}_{2} \mathrm{Se}_{2}$ and $\quad \mathrm{S} 5$ mixture of $\mathrm{Ph}_{2} \mathrm{Se}_{2}$ and $\mathrm{Ph}_{2} \mathrm{~S}_{2}$.

Figure S10. XRD pattern of CdS, CdSe compared with CdSeS NCs obtained from $\mathrm{Me}_{2} \mathrm{~S}_{2}$ and $\mathrm{Ph}_{2} \mathrm{~S}_{2}$ as source of sulfur.

Figure S11. TEM image of CdSe NCs obtained from reaction of Cd(oleate) $)_{2}$ with 1:1 ratio mix- $\quad$ S5 ture of $\mathrm{Ph}_{2} \mathrm{Se}_{2}$ and $\mathrm{Ph}_{2} \mathrm{~S}_{2}$.

Figure S12.UV-Vis spectrum of CdTe, CdTeS and CdTeSe

Figure S13. XRD pattern of CdS, CdTeS and CdTe NCs

Figure S14. EDAX analysis of CdTeSe NCs. 


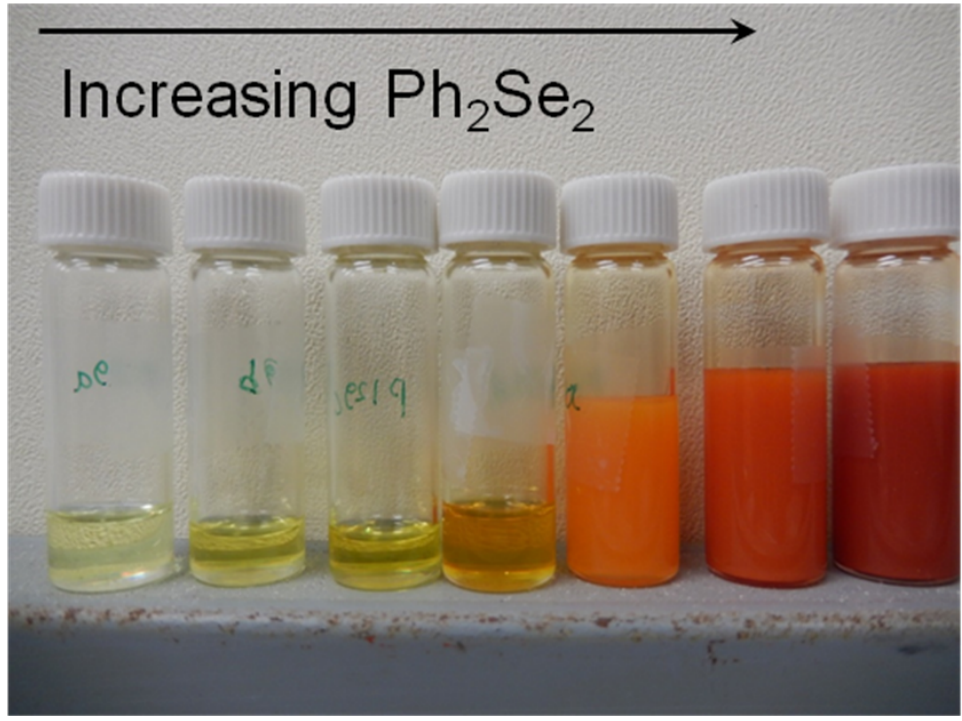

Figure S1. Image of samples of NCs obtained from reactions with different ratio of $\mathrm{Me}_{2} \mathrm{~S}_{2}$ and $\mathrm{Ph}_{2} \mathrm{Se}_{2}$, more NCs obtained from reactions with higher amount of $\mathrm{Ph}_{2} \mathrm{Se}_{2}$

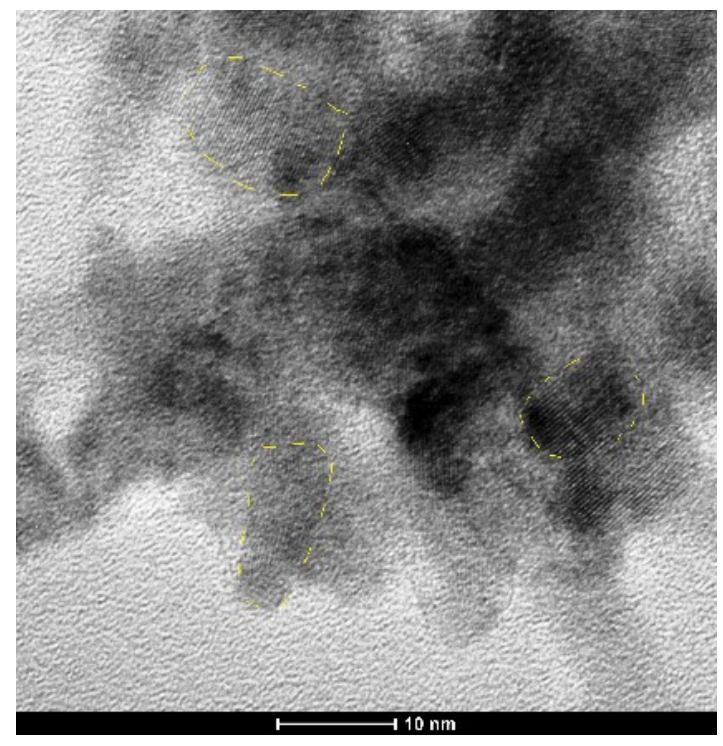

Figure S2. HRTEM image of HSQDs obtained from dichalcogenides with $12 \% \mathrm{Ph}_{2} \mathrm{Se}_{2}$. 

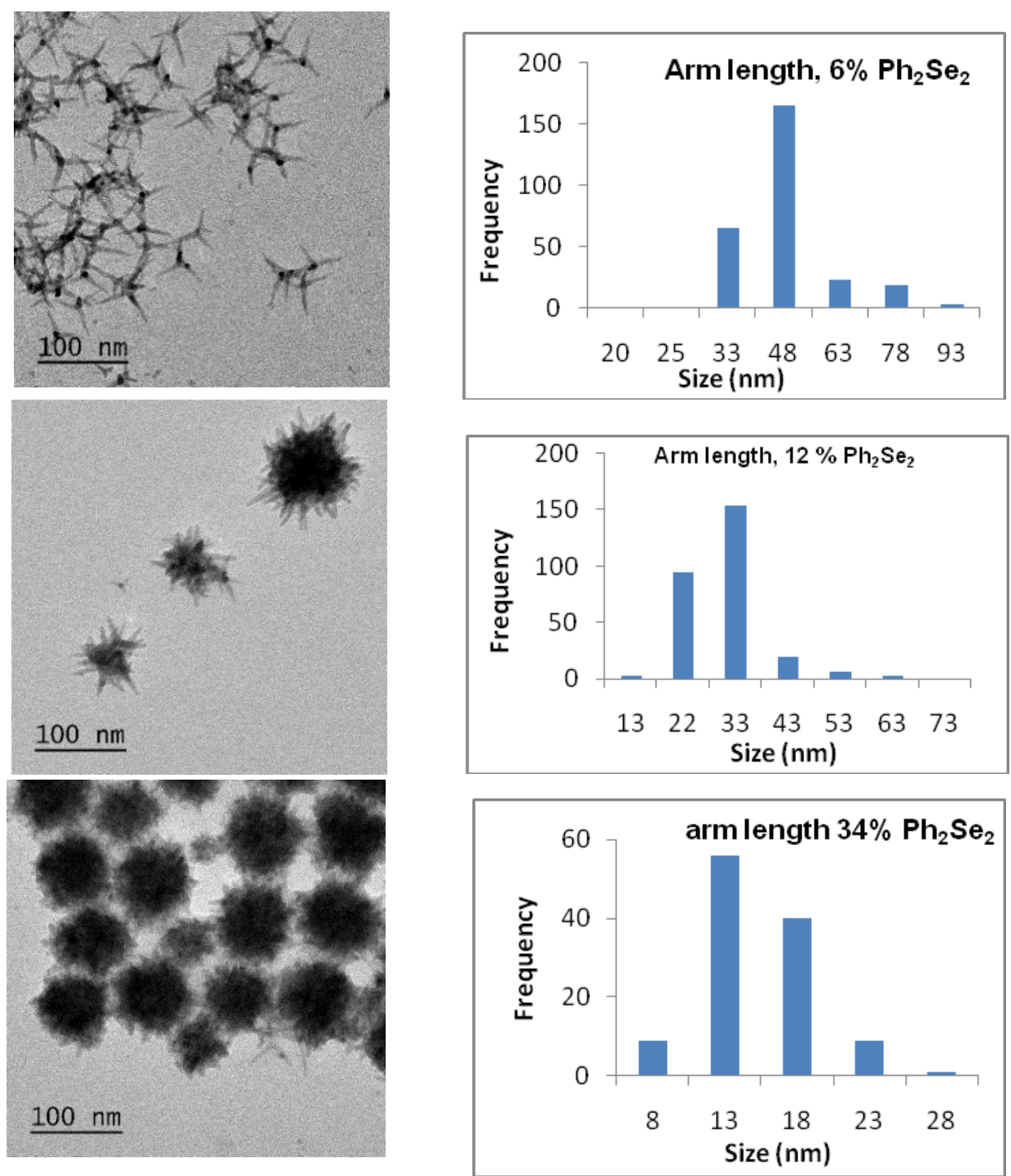

Figure S3. TEM image and histogram of arm length of NCs obtained from samples with $6 \%, 12 \%$ and $34 \% \mathrm{Ph}_{2} \mathrm{Se}_{2}$.

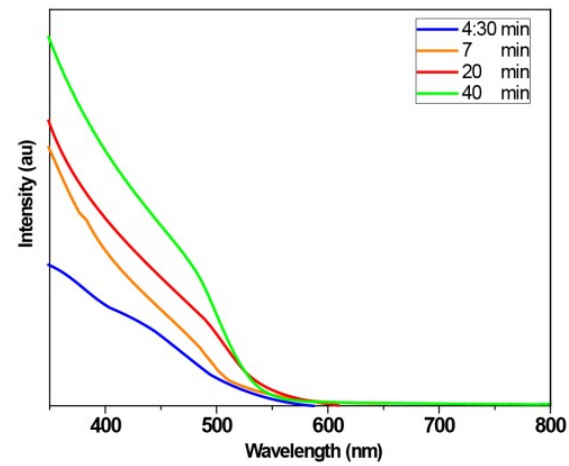

Figure S4. UV-Vis spectrum of NCs obtained from dichalcogenides with $12 \% \mathrm{Ph}_{2} \mathrm{Se}_{2}$ over time. 


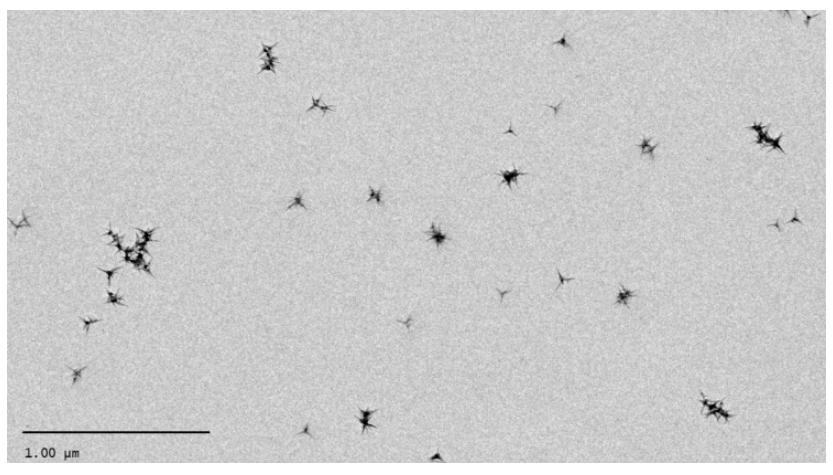

Figure S5. Individual and aggregated branched NCs obtained from $10 \% \mathrm{Ph}_{2} \mathrm{Se}_{2}$

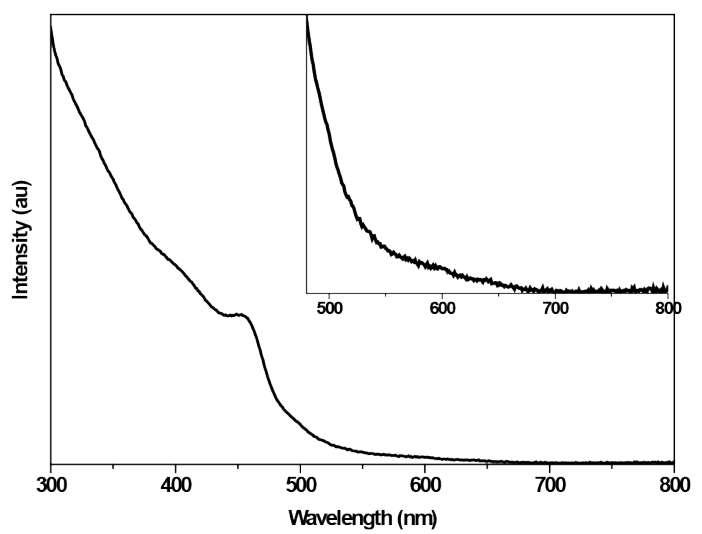

Figure S6. UV-Vis spectrum of NCs obtained from reaction of diluted mixture at $250{ }^{\circ} \mathrm{C}$.

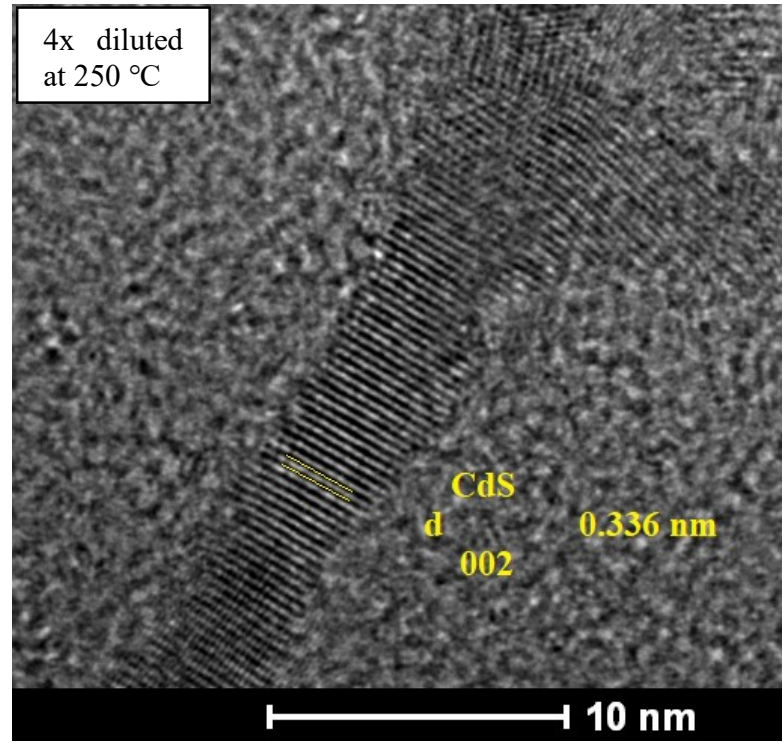

Figure S7. HRTEM image of NCs obtained from reaction of diluted mixture containing $10 \% \mathrm{Ph}_{2} \mathrm{Se}_{2}$ at $250{ }^{\circ} \mathrm{C}$. 

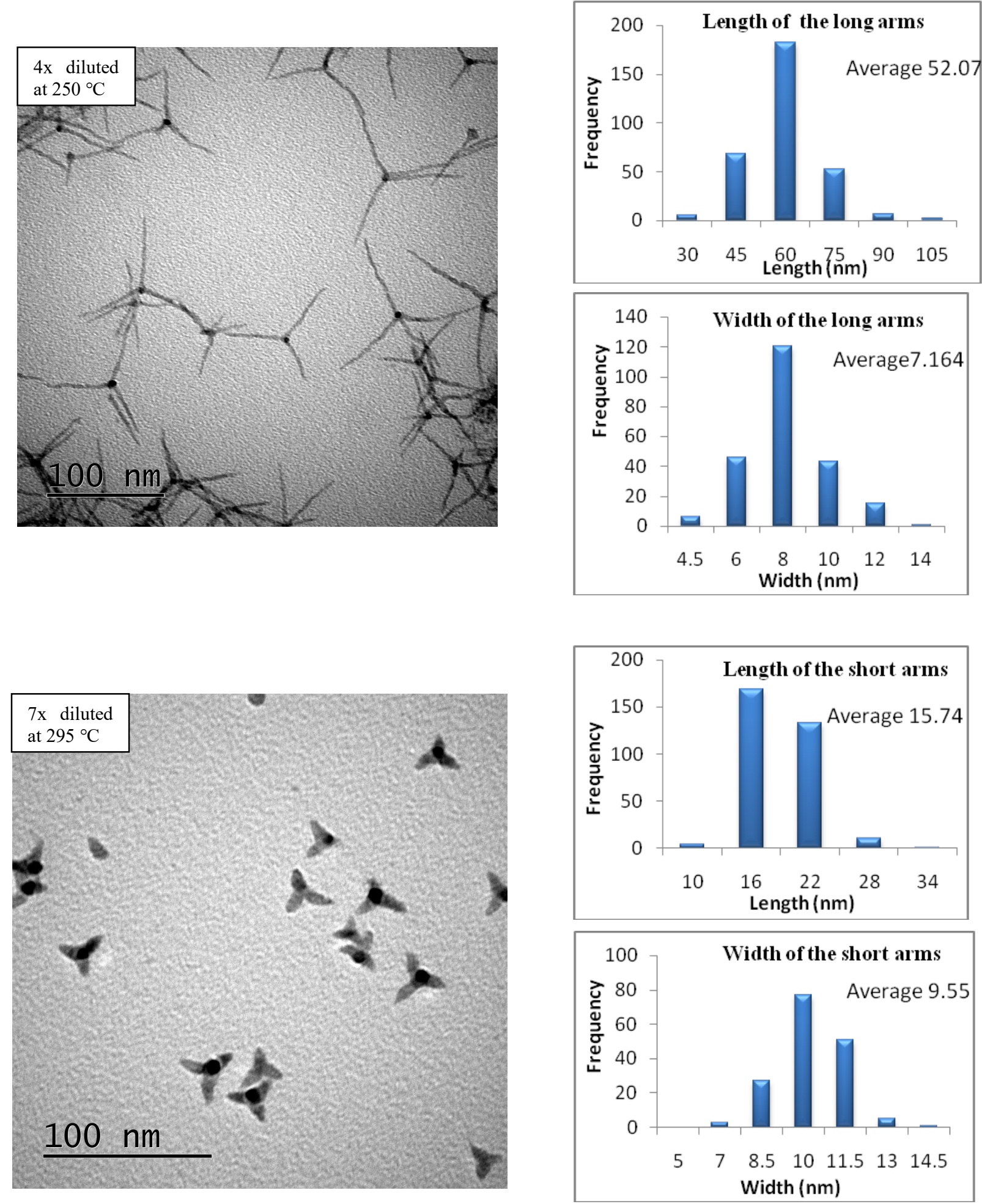

Figure S8. TEM images and histogram of arms length and thickness of NCs obtained from samples $10 \% \mathrm{Ph}_{2} \mathrm{Se}_{2}$ at different temperatures. 


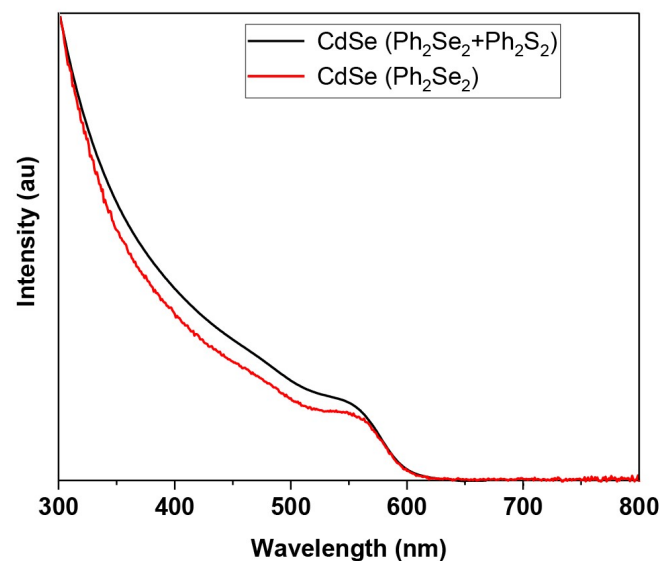

Figure S9. UV-Vis spectra of CdSe NCs obtained from reaction of Cd(oleate) $)_{2}$ with $\mathrm{Ph}_{2} \mathrm{Se}_{2}$ and mixture of $\mathrm{Ph}_{2} \mathrm{Se}_{2}$ and $\mathrm{Ph}_{2} \mathrm{~S}_{2}$.

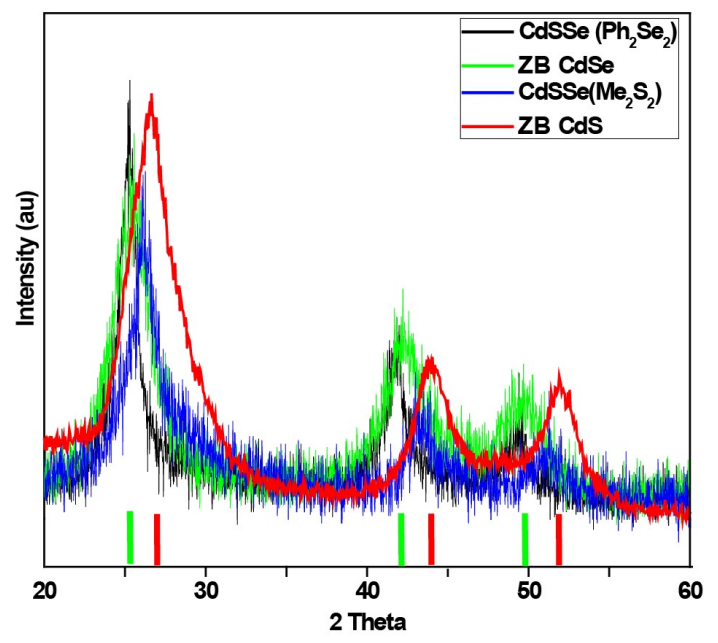

Figure S10. XRD pattern of CdS (JCPDS files No. 06-0314 and 02-0563), CdSe (JCPDS file No. 19-0191) compared with CdSeS NCs obtained from $\mathrm{Me}_{2} \mathrm{~S}_{2}$ and $\mathrm{Ph}_{2} \mathrm{~S}_{2}$ as source of sulfur.

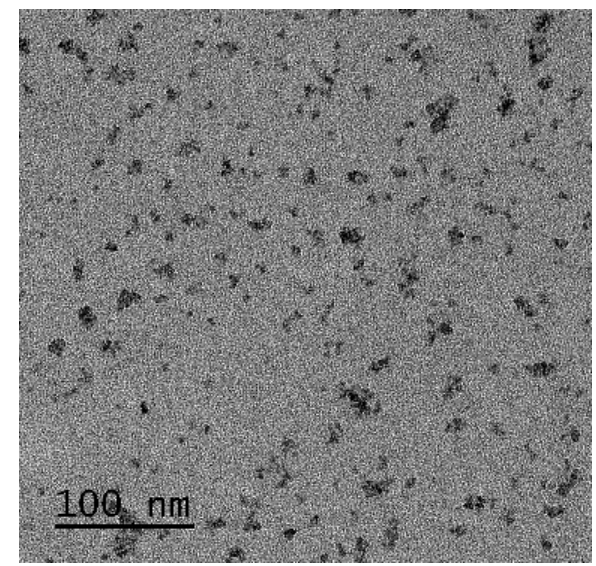

Figure S11. TEM image of CdSe NCs obtained from reaction of Cd(oleate) $)_{2}$ with 1:1 ratio mixture of $\mathrm{Ph}_{2} \mathrm{Se}_{2}$ and $\mathrm{Ph}_{2} \mathrm{~S}_{2}$. 


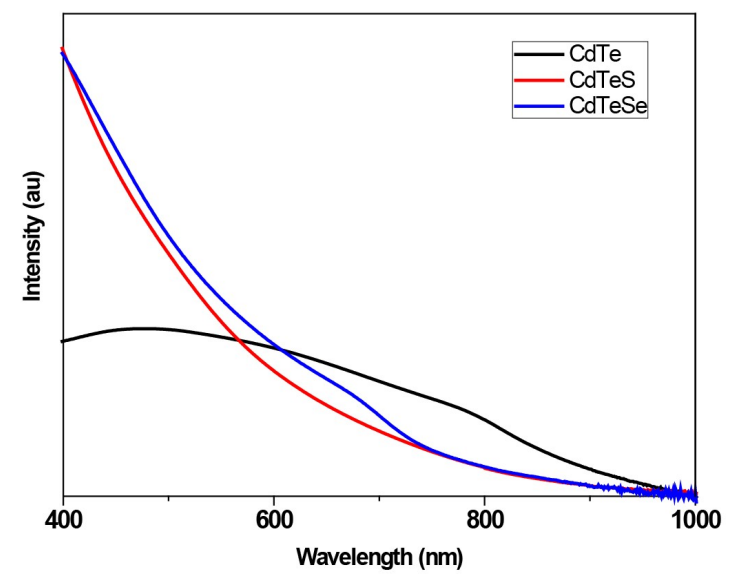

Figure S12.UV-Vis spectrum of CdTe, CdTeS and CdTeSe
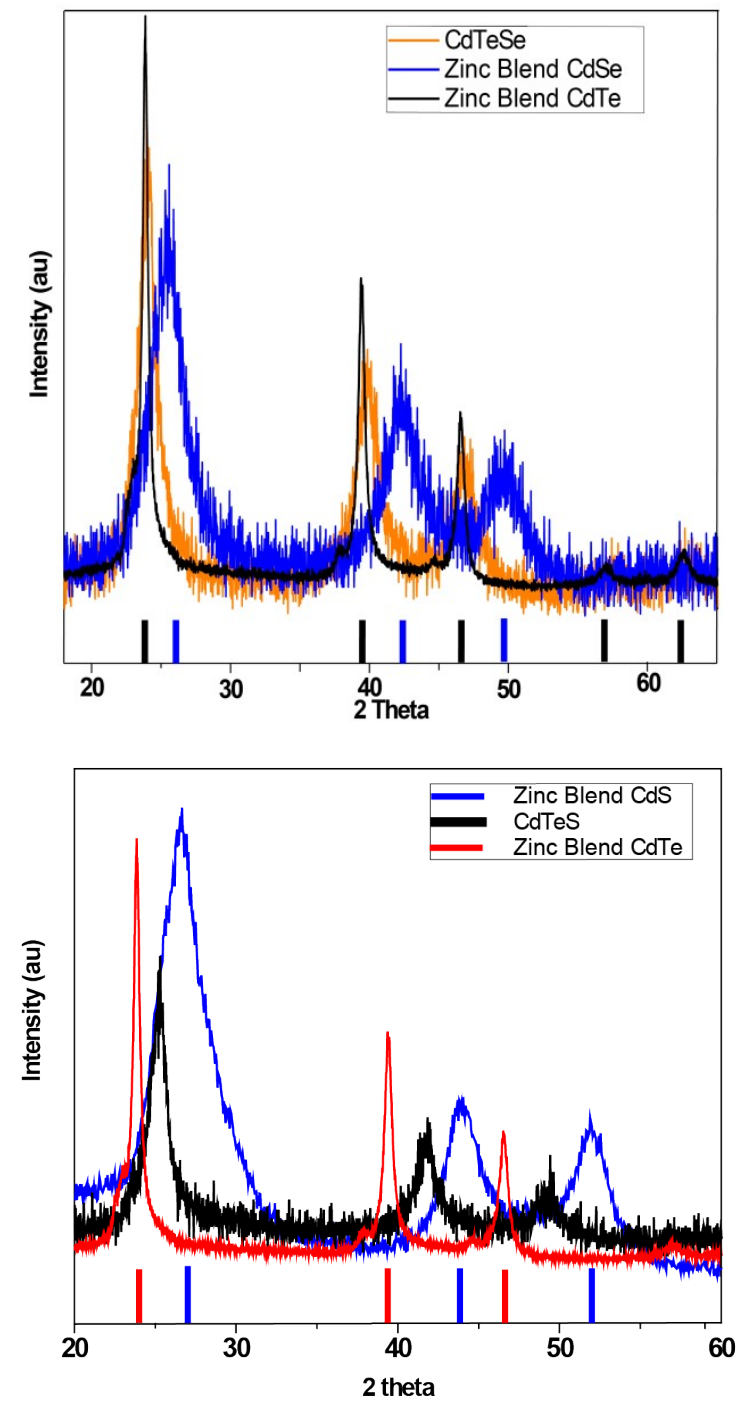

Figure S13. XRD pattern of CdS (JCPDS files No. 06-0314 and 02-0563), CdTeS, CdTeSe, CdSe (JCPDS file No. 19-0191) and CdTe (JCPDS files No. 15-0770) NCs 

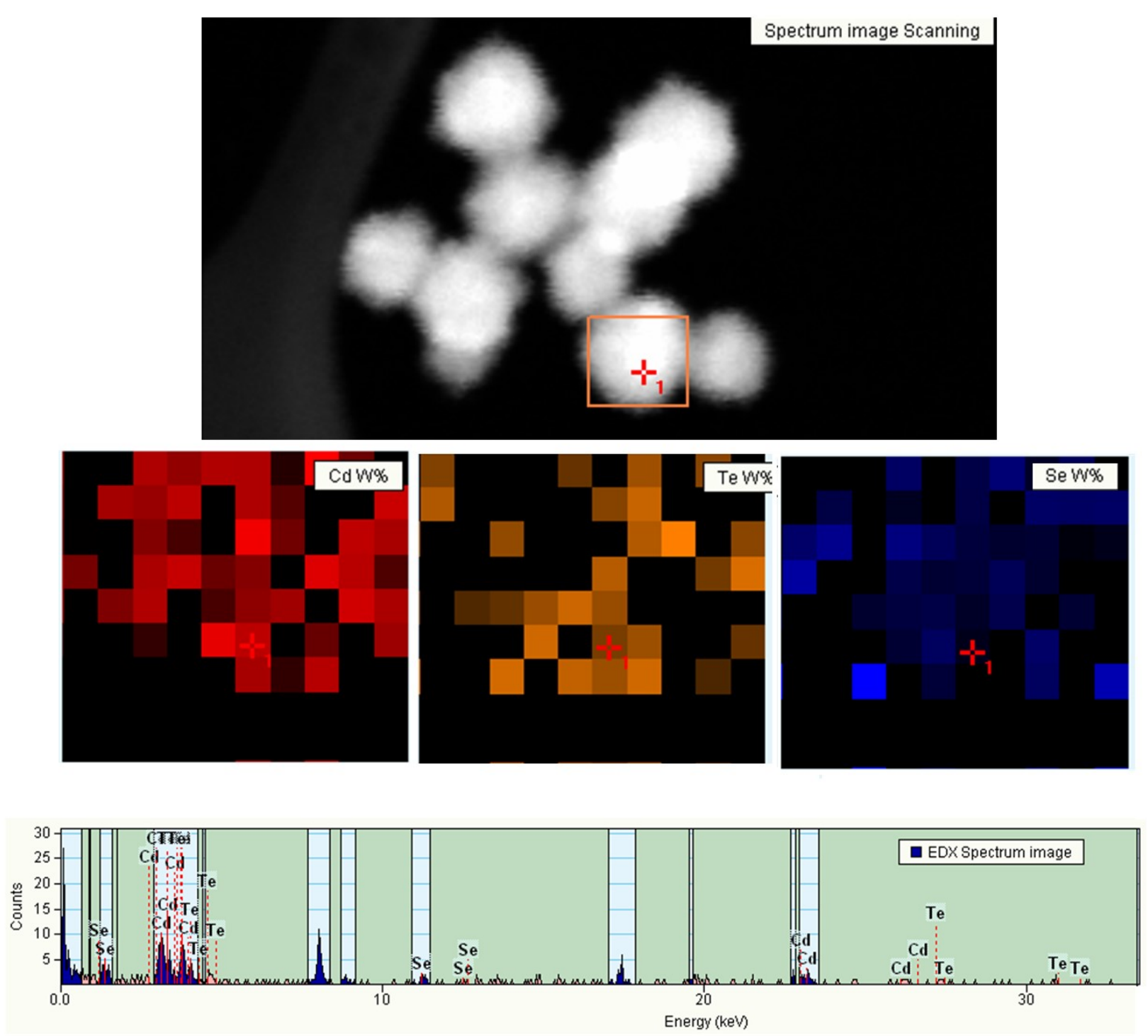

Figure S14. EDAX analysis of CdTeSe NCs. 